\title{
Forestry and Aircraft
}

By Torvald Hassel, District Forester, Wayagamack Pulp and Paper Company, Ltd.

The keynote of today is efficiency. The man who can accomplish the most for least money is the man who will survive the present keen competition. That means we must make use of every technical device available, and that the old manual methods of labor are disappearing.

The forester should do as business men everywhere are doing; that is, follow the development from manual labor to technical methods. One development is of immense importance to us as a time and labor saver-the flying machine. Take the case of a company considering the purchase of a new limit. Everyone who has made explorations knows what hardships are met in unexplored country. There must be heavy portaging over windfalls, and one is pursued by black flies and mosquitoes; even a first-rate bushman cannot cover a large area in a day. The cost in labor, hardship, and money is high, before it can be decided whether the limit is worth buying.

From an aeroplane, the prospective buyer can cruise in comfort the whole limit in a few hours. From the air, he will obtain a very good idea of the area; the proportion between burn and green; the percentage of productive timberland and its density; the relative proportions of hardwood and softwood; logging and driving conditions; etc. Should he wish to look closely at the standing timber, the plane can land him on almost any lake, and a ground cruise can be made from there. The great advantage is that the explorer sees everything in a short time, and gets a clear impression of all the important features.

As another illustration, a company which has had its lim:ts surveyed and estimated in detail, suffers a big fire on its territory. At present, in order to know approximately what is burnt, and whether it can be salvaged, a field cruise must be made, consuming much time and money. Again, the green area must be mapped as well as the burn, involving a great deal of time. What an advantage an aerial cruise offers in such a case. A sketcher may be sent up to make a small sketch map, showing only lakes, streams, and heights of land. In three or four hours he can do more valuable work, both as to quantity and accuracy, than two ground parties in four weeks. If he is but a fair sketcher, his work will be more than good enough to use as a base for planning cutting operations.

T'o give a concrete example: In one district an area of approximately 35 square miles was properly mapped for a road location, but was not cruised, and a fire went through this area after the mapping. A survey had to be made to decide the quantity of burnt timber before it could be salvaged. It was decided to try aerial sketching instead of ground survey. In one hour and fortyfive minutes, the sketch was finished, showing boundary lines for burnt and green timber, burnt and green non-merchantable t:mber swamps, etc. To supply smal-

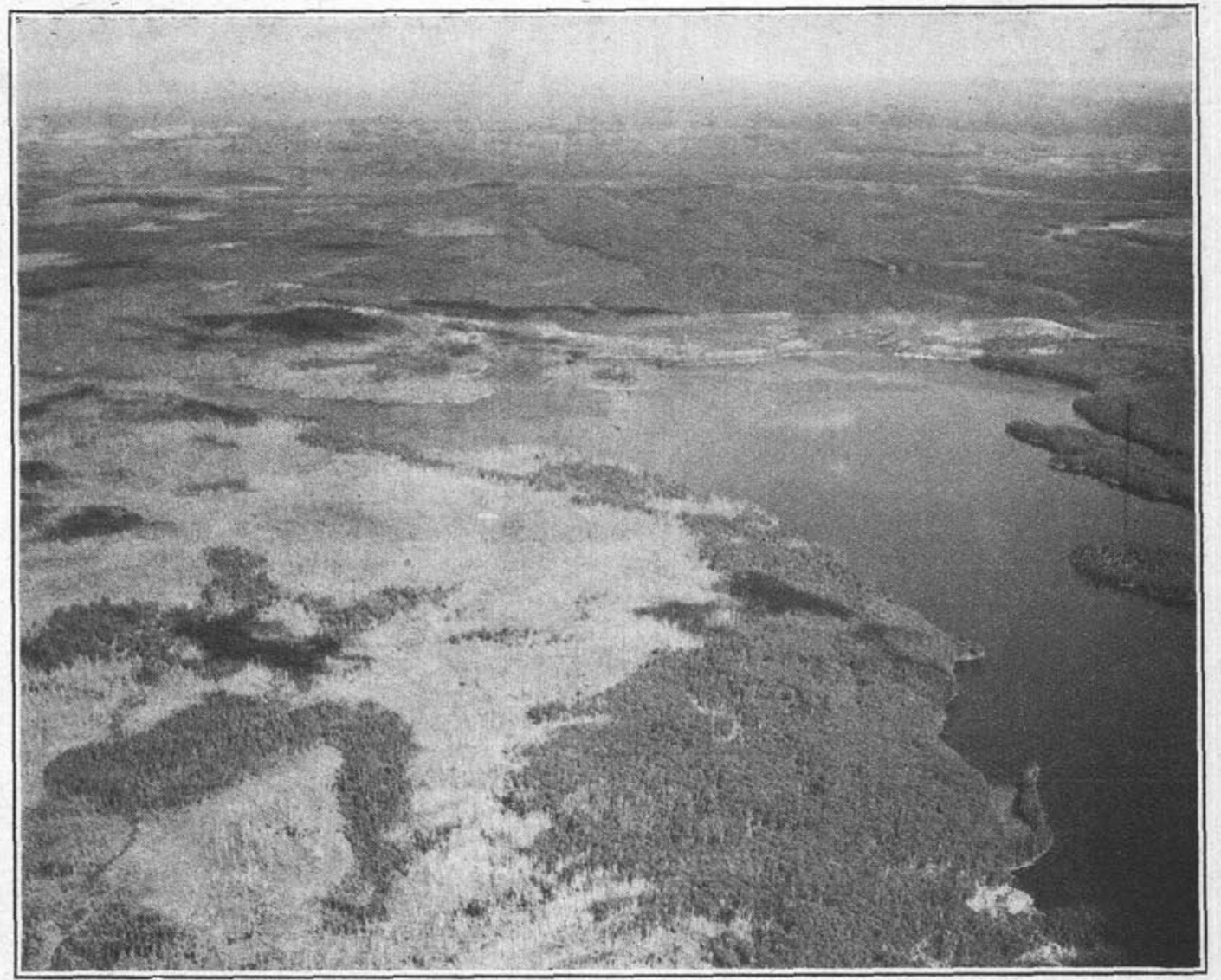

Mixed soft and hard woods, right centre foreground; central part of picture shows burnt areas with dead white birch still standing. This view shows how clearly timber conditions can be seen from the air.-Photo by Fairchild Aerial Surveys Co. (of Can.) Ltd. 
ler details, a series of oblique pictures was made, covering the same area. The sketch was compared with the obliques and the stands laid down on the map. With this new map, one forester went out into the field alone. In four days he covered the whole area, deciding types; he made stand descriptions and counted trees per acre. The eost of the aerial sketch was less than one-half of what a ground check would have cost, to say nothing of the greater speed in making estimates. It may be pointed out here that aerial sketches should usually be combined with a series of oblique photographs, as in this case. The cost is low, and they are of great value to the sketches, since by their aid he ean correct any errors in his work; and they show smaller details than he may have on his map.

The use of aerial photography is rapidly increasing in surveying forests. An aerial survey in combination with a ground survey, gives exeellent maps and better $\eta$ estimates than a ground, survey alone - and for less money. Boundaries of types, in particular, can be decided with great accuracy; a man easily becomes accustomed to working on aerial pictures, and can pick out types very quickly. $\mathrm{He}$ can even determine roughly the number of trees per acre.

Another field in which aeroplanes are being used is that of fire fighting and patrol. Two hydroplanes can cover a large territory each day, and they can report quickly any fire observed. Thiey ean carry men and equipment to a fire; and within a couple of hours after it is reported, a crew with full equipment ean be at the spot ready to start the fight, without having exhausted their strength in traveling and portaging.

During the last ten years there have been great developments made in both machines and photographic equipment and skill, and they are rapidly being recognized as a necessity in the proper handling of our timber limits, making for a saving in money and time, and for an increase in efficiency.

-Pulp and Paper Magazine 